\title{
A regulação do planejamento público e o conselho municipal de saúde
}

The regulation of the public planning and the local health council

\section{Oswaldo José Barbosa Silva}

Graduado em Direito, Especialista em Direito Sanitário. Subprocurador-Geral da República, Cidade, Brasil.

Resumo: Apresenta-se uma visão das dificuldades que sofre o modelo de estruturação do controle social na saúde pública, por meio dos conselhos de saúde, que exsurgem de seu dever de deliberar sobre o planejamento e fiscalizar a execução das ações e serviços públicos de saúde no âmbito municipal, estabelecido que o plano de saúde e os programas anuais de saúde que lhe seguem materializam a organização que se espera para a prestação desse serviço público, que atende um direito público subjetivo de matriz constitucional. Para tanto foi feita uma revisão de literatura e uma pesquisa documental. Observou-se que falta qualificação técnica dos conselheiros para discutir assuntos relacionados com planejamento de saúde, financeiro e orçamentário como se pode observar em pesquisas de campo realizadas em Municípios do Nordeste Brasileiro, dos Estados de Mato Grosso e Goiás e no município de Belo Horizonte (MG). Todavia, essas deficiências não diminuem a importância do modelo de participação social adotado por meio dos conselhos de saúde, devendo ser construídas estratégias para enfrentá-las.

Palavras-chave: Direito Sanitário; conselho municipal de saúde; Plano de Saúde; regulação do planejamento.

Key-words: Health Law; local health council; Health Plan; regulation of health planning. 


\section{Introdução}

O controle social na saúde pública foi resultado dos esforços políticos do assim denominado movimento da reforma sanitária brasileira que, expressos na VIII Conferência Nacional de Saúde (1986), esse esforço foi recompensado pelos Constituintes de 1988, de forma que o controle social foi previsto na atual Constituição quando esta determinou a participação da comunidade como uma das diretrizes do Sistema Único de Saúde (SUS). No entanto, somente dois anos depois, com o advento das Leis $\mathrm{n}^{\text {os }} 8.080 / 90$ e 8.142/90, foram formalmente instituídos e tiveram sua constituição regulada e fomentada pelo Ministério da Saúde por meio de Portarias que instituíram as Normas Operacionais Básicas (NOB) do SUS, expedidas, sucessivamente, em 1991, 1993 e 1998. Registre-se que criação dos conselhos municipais de saúde depende de lei municipal, contudo seu funcionamento deve observar as diretrizes do SUS.

A atribuição legal dos conselhos de saúde está prescrita no art. 1ำ, inciso II, da Lei $n^{\circ}$ 8.142/90, que Ihe confere caráter permanente e deliberativo para atuar na formulação de estratégias e no controle da execução da política de saúde na instância correspondente, inclusive nos aspectos econômicos e financeiros. Assim, é sua função inarredável deliberar sobre o plano de saúde, sobre a programação anual de saúde e, depois, fiscalizar-Ihes a execução.

Importa saber o quão importante é para os conselheiros municipais de saúde o conhecimento técnico e prévio do planejamento público em geral, do planejamento específico para a saúde.

Este conhecimento, como pretende o presente artigo revelar, é complexo. No que tange ao planejamento público em geral existem normas de estatura constitucional e legal a regê-lo. A Constituição Federal, em seu art. 165 institui como instrumentos do planejamento público o Plano Plurianual, a Lei de Diretriz Orçamentária e a Lei Orçamentária Anual. Estabelece, também, o financiamento da saúde pública, nos termos da Emenda Constitucional $n^{\circ} 29 / 2000$. No plano legislativo, o planejamento público deve observar os já citados instrumentos, mas ainda, a Lei de Responsabilidade Fiscal (Lei Complementar no 101/2000) e a Lei de Finanças Públicas (Lei nํ 4.320/64). Mais recentemente a Lei Complementar no 141/2011, 
impôs regras de elaboração orçamentária em face dos aportes financeiros para a saúde.

No âmbito da saúde pública, propriamente dita, o planejamento municipal encontra matriz legal na Lei no 8.080/90, arts. 15, inciso VIII e 18, incisos I e II.

No plano infralegal, o Ministério da Saúde instituiu o Sistema de Planejamento do SUS (PlanejaSUS) e das orientações gerais acerca dos seus instrumentos, pactuadas na Comissão Intergestores Tripartite e aprovadas pelas Portarias № 3.085/GM e № 3.332/GM, do Ministério da Saúde, ambas de 2006, donde se extrai: "o Plano de Saúde (PS) é o instrumento básico que, em cada esfera, norteia a definição da Programação Anual das ações e serviços de saúde prestados, assim como da gestão do SUS". Segundo a Portaria 3.332/GM/2006 citada, o Plano "apresenta as intenções e os resultados a serem buscados no período de quatro anos, expressos em objetivos, diretrizes e metas” ( $\$ 1^{\circ}$ do art. $2^{\circ}$ ) (Brasil, 2009).

O plano de saúde é a base, portanto, para a definição e a implementação de todas as iniciativas no âmbito da saúde. Ou seja: é a referência para os processos de planejamento regional e formulação de programações, projetos, entre outros. Assim, deve ser valorizado como o instrumento central de planejamento, sendo necessário que todas as iniciativas estejam nele contidas, a partir dos seus diversos componentes. Trata-se, enfim, de instrumento no qual precisam estar refletidas as necessidades e peculiaridades próprias de cada esfera, constituindo referencial para a execução, o acompanhamento, a avaliação e a gestão do sistema de saúde (Brasil, 2009).

O pleno e eficaz funcionamento dos Conselhos Municipais de Saúde é um objetivo ainda não alcançado (Martins et al. 2008, e Labra, 2006) e que impõe um contínuo e trabalhoso esforço de seu aprimoramento, com o qual este artigo pretende contribuir.

As dificuldades deste modelo de controle social e participação societária em uma incumbência tipicamente governamental são, no plano municipal, há muito conhecidas: adesão escassa ou inexistente da comunidade; ausência de publicidade de sua existência e de suas atividades; apequenamento de seu papel institucional; 
dificuldades no funcionamento interno; hipertrofia do papel dos gestores de saúde; irregularidades na composição, representação e representatividade (Labra, 2006).

Nesse sentido, o presente artigo pretende investigar as dificuldades que o modelo de participação social estruturado nos Conselhos Municipais de Saúde enfrenta para realizar a sua atividade de deliberar sobre o planejamento e fiscalizar a execução das ações e serviços públicos de saúde no âmbito municipal.

\section{Metodologia}

Foi feita uma revisão de literatura sobre o tema, em especial, trabalhos científicos que abordaram as dificuldades enfrentadas pelos Conselhos Municipais de Saúde para a realização de suas competências. A seleção desses artigos foi realizada sob o critério de que "efetividade "e "capacitação deveriam ser as palavraschave para a pesquisa, porquanto seu objeto era mensurar o grau de dificuldade que os conselheiros municipais de saúde suportam em face de um eventual débito de capacitação técnica em especial diante da complexidade do arcabouço normativo. Procurou-se listar artigos não muito antigos, limitando a pesquisa a artigos publicados após o ano de 2006. Para a localização dos artigos foi utilizada a Livraria Científica Eletrônica Online, projeto da FAPESP - Fundação de Amparo à Pesquisa do Estado de São Paulo, em parceria com a BIREME - Centro Latino-Americano e do Caribe de Informação em Ciências da Saúde com o apoio do CNPq- Conselho Nacional de Desenvolvimento Científico e Tecnológico (www.scielo.br).

Também foi realizada pesquisa documental no âmbito dos documentos públicos do PlanejaSUS, bem como textos legais pertinentes ao tema, todos localizados no sítio do Ministério da Saúde e da Presidência da República, na rede mundial de computadores.

\section{Plano de Saúde e controle social}

Não é dever do Conselho Municipal de Saúde elaborar o Plano de Saúde, mas da gestão municipal de saúde, de acordo com a conformação que Ihes dá a 
administração pública municipal. O plano de saúde é uma exigência legal (art. 15, VIII, da Lei 8.080/90), informa a elaboração da proposta orçamentária do município (art. 15, X, da Lei 8.080), deve compatibilizar-se com a disponibilidade de recursos, seu financiamento será previsto na proposta orçamentária e não haverá transferência de recursos para ações que não estejam previstas em seu bojo (art. 36 e 37 da Lei 8.080). Mais recentemente o plano de saúde foi objeto da Lei Complementar $\mathrm{n}^{-}$ 141/2012, que estabeleceu novas prescrições para fortalecer a sua importância, de modo que, para o fim de apuração da aplicação do mínimo dos valores que, constitucionalmente (art. 77, do ADCT) e nessa própria lei, devem ser aplicados em ações e serviços públicos de saúde, essas ações devem atender, dentre outras diretrizes, a que determina que estejam em conformidade com objetivos e metas explicitados no Plano de Saúde (art. $2^{ }$, inciso II). Mais grave é a prescrição que o rateio dos recursos da União (e dos Estados) em favor dos municípios pode ser condicionado à apresentação do Plano de Saúde.

Sua elaboração, mesmo para o gestor de saúde experiente, não é tarefa fácil. Mesmo para um pequeno município, sua formulação deve conter o planejamento para o prazo de quatro anos e se divide em dois momentos: a análise situacional e a formulação de objetivos, diretrizes e metas.

Resumidamente, a análise situacional deve considerar os dados para a identificação do município e da própria secretaria municipal de saúde; a situação de saúde do município; a informação de toda a estrutura da rede de atenção do município (atenção integral à saúde) bem como sobre a produção dos serviços de saúde; a análise da gestão municipal da saúde e a definição dos problemas prioritários observando-se, neste último caso três eixos: as condições de saúde da população; os determinantes e condicionantes da saúde, sob a ótica de sua magnitude, transcendência, magnitude e custos (Brasil, 2009).

A formulação de objetivos, diretrizes e metas estão vinculados à análise situacional e devem ser orientados pelos princípios que regem o SUS: universalidade, integralidade e gratuidade, de modo a propiciar as ações e serviços de saúde propriamente dito. Por fim, devem ser construídos os indicadores de resultados, instrumento necessário à medição do cumprimento das metas. 
Resulta óbvio que uma tarefa de tal magnitude é um desafio mesmo para os grandes municípios do país. Ainda na instância dos formuladores dos planos de saúde, Sulpino (2008, p. 1570) dá uma noção da dificuldade de seu planejamento:

A discussão do planejamento em saúde no SUS parece já ter ultrapassado as questões metodológicas, quanto à definição de instrumentos para sua realização, evidenciando-se na atualidade a necessidade de definição de fluxos e mecanismos de interligação entre os diversos atores, tanto do ambiente interno quanto externo a cada esfera de governo. Quando a questão tange ao planejamento no ambiente intra-organizacional (Secretarias de Saúde e Ministério da Saúde), geralmente o tema é tratado como assunto de um setor específico, responsável pelo planejamento da instituição. Nesta lógica, há escasso envolvimento dos profissionais de saúde, que seriam responsáveis pelo alcance dos objetivos e metas propostos. Como estes não fazem parte do processo de sua definição, invariavelmente se observa o distanciamento entre o plano estabelecido e os resultados alcançados. O plano constitui-se apenas de um conjunto de intenções que figuram em um documento, mas que não levam a resultados práticos. O planejamento acaba sendo feito para o cumprimento de exigência legal, em vez de instrumento para a implementação da política de saúde ou como base para a alocação de recursos.

Percebe-se que, mesmo na instância elaborativa do Plano de Saúde, cujo produto deve ser levado ao Conselho de Saúde, existem problemas que podem contaminar sua eficácia e, mesmo neste quadro, o Plano de Saúde deve ser objeto de apreciação e deliberação pelo órgão do controle social, que por sua vez padece de enormes dificuldades para seu próprio funcionamento.

Basta passar os olhos pela Resolução n 333 , de 4 de novembro de 2003, do Conselho Nacional e Saúde, onde, em sua Quinta Diretriz, são enumerados vinte e quatro competências e atribuições para os Conselhos e considerar que sua composição é voluntária, sendo considerada de relevância pública apenas para justificar faltas ao trabalho, como se vê na terceira diretriz do mesmo documento.

Essas dificuldades acima insinuadas têm sido alvo de numerosos estudos, dos quais transcrevem-se, abaixo, alguns excertos. Abertamente, aqui se trata da dificuldade dos Conselheiros Municipais de Saúde lidarem e intervirem propositivamente na deliberação, tendo por objeto o Plano Municipal de Saúde. No campo da pesquisa empírica, podemos citar alguns autores que debruçaram-se sobre a matéria. Uma análise sobre a efetividade deliberativa dos Conselhos Municipais de Saúde no nordeste assevera: 
Há também um outro aspecto que não pode ser ignorado e que diz respeito a alguma dificuldade manifesta pelos conselheiros quanto à intervenção propositiva sobre a política e sobre o orçamento. A criação de câmaras técnicas na estrutura dos conselhos tem o potencial de produzir alterações nesta situação, mas os resultados de sua existência ainda precisam ser verificados. O que se tem de concreto são demandas constantes por processos de capacitação dos conselheiros, não só nas reuniões dos conselhos, mas também em suas Conferências municipais, estaduais e nacionais, que têm deliberado no sentido de que sejam criadas condições para que seja reduzida a assimetria informacional entre os diversos segmentos que têm assento nos conselhos e apontado o processo de formação de conselheiros como uma estratégia para isso.

Sabe-se que têm sido empreendidas diversas iniciativas no sentido de formação de conselheiros e multiplicam-se ações educativas voltadas para suprir esta demanda. No entanto, ainda se percebe muito pouca intervenção dos conselheiros na proposição ou na alteração da política e do orçamento para as áreas, mesmo quando as normas operacionais condicionam 0 repasse de recursos financeiros do governo federal aos governos municipais à aprovação tanto de planos de gestão da política (aí incluída a proposta orçamentária), quanto de prestações de conta (das ações desenvolvidas e dos recursos utilizados - Relatórios de Gestão). Isso faz com que, obrigatoriamente, esses temas sejam tratados nos conselhos e ganhem visibilidade, mas ainda assim, tem conselhos que parecem apenas cumprir as formalidades de aprovação desses documentos, pois são temas muito pouco deliberados em suas reuniões.

A prevalência do exercício do controle indica que os conselhos despendem mais energia sobre decisões já tomadas e em execução, muitas delas não compartilhadas pelos governos com os conselhos. Isso pode significar que os conselhos estão tendo muito pouca capacidade de intervenção nos rumos da política em si, que é definida nas fases de elaboração dos orçamentos e dos planos municipais de saúde e da criança e do adolescente. O estudo possibilitou constatar, inclusive, a pouca discussão que existe nos conselhos sobre o financiamento da política e os critérios de repartição dos recursos públicos geridos por eles. Neste sentido, entende-se que os conselhos têm menor efetividade deliberativa quando prevalece a função de controle sobre a função propositiva, o que se manifestou em todos os casos estudados." (Cunha, 2007, p. 21)

Enquanto em outro estudo, este abarcando municípios de Goiás e Mato

Grosso do Sul, informa, significativamente que:

As deliberações parecem pautar-se mais por um discurso em defesa dos princípios do SUS do que por considerações técnicas ou orçamentárias, como sugere o fato de que apenas um informante soube participar o percentual dos gastos municipais aplicados à saúde e nenhum sabia o percentual dos gastos com atenção básica. Mesmo assim, produzem efeitos. Na visão dos informantes, o conselho contribui para a melhoria da atenção básica, redireciona prioridades e torna mais transparente a alocação de recursos (sete respostas 
positivas), melhora a eficiência da gestão pública (seis respostas positivas) e a relação entre a Secretaria de Saúde e a comunidade (quatro respostas positivas). (Van Stralen et alii, 2006, p. 629)

Mesmo em um grande centro urbano, como Belo Horizonte (MG), de modo a demonstrar que este não é um problema dos pequenos municípios, constatou-se que:

A questão da informação, como ponto crucial para se efetivar a participação de todos os envolvidos, é muito bem discutida por Guizardi e Machado (2005) quando esclarecem que realmente fica muito difícil participar em quaisquer instâncias da qual o sujeito não se percebe 'agente de constituição e produção da política'. Assim, os modos pelos quais essas informações são produzidas e disseminadas têm sido ao longo da nossa história política território avesso à participação da população. Quem detém o poder de construir a informação e divulgá-la também tem o poder de considerá-la verdade, à revelia das demandas para quem foram construídas. No caso da saúde, as políticas acabam sendo criadas PARA e não COM os sujeitos, comprometendo todo o processo. Os conceitos são sempre carregados de noções técnicas, e há uma dificuldade muito grande na apropriação do conteúdo das políticas públicas. (Santos et al., 2011, p. 490)

Noutro campo, o da literatura, a dificuldade acima constatada é afirmada por Labra (2006, p. 210), quando sintetiza, como um dos problemas que fustigam os Conselhos de Saúde, o desvio de seu papel institucional:

O CS é muito valorizado por todos aqueles que o conhecem ou dele participam. Entretanto, predomina a impressão de que é um espaço para reivindicações específicas ou denúncias pontuais. A maior parte do tempo de cada reunião mensal é gasta na discussão de assuntos internos, sendo raros os debates de temas substantivos. Quanto ao Plano de Saúde, ao Orçamento e ao Relatório de Gestão, os conselheiros não têm papel relevante na discussão, convertendo-se em um mero ritual a aprovação dessas importantes peças da gestão.

Esse desvio, o de se converter o Conselho de Saúde em um mero homologador das peças de planejamento da saúde que lhe são submetidas, decorre do fato de que os conselheiros, especialmente os representantes dos usuários, são tecnicamente despreparados para perceberem a lógica de funcionamento e as necessidades do sistema de saúde, razão pela qual os gestores, normalmente apoiados por quadros especializados, exercem hegemonia nos conselhos, definindoIhes as agendas e induzindo os conselheiros à aprovação das decisões do próprio gestor, à míngua da capacidade dos conselheiros de opor-lhes argumentos técnicos ou jurídicos (Martins et al., 2007). Acresço à dificuldade de compreender os argumentos técnicos de saúde pública o cipoal legislativo que regula o planejamento 
público e que sujeita, não só os representantes dos usuários, mas todos os demais conselheiros.

E é esse Conselho Municipal de Saúde que, diante de seu dever de apreciar e deliberar sobre o Plano Municipal de Saúde e, em decorrência, sobre a Programação Anual de Saúde e o Relatório Anual de Gestão, esbarra na complexidade da regulação do planejamento público, mormente sem poder, de regra, contar com o apoio técnico imprescindível para o entendimento da matéria.

A primeira necessidade é o conhecimento do financiamento da saúde, hoje regulado pelo art. 198, da Constituição Federal e pela Lei Complementar no 141/2011, que, a partir de sua vigência, afastou a aplicação do art. 77, do ADCT (conferir o § 4ㄴ, desse artigo). Não é possível planejar sem a certeza que as ações planejadas encontrarão recursos financeiros para sua execução. Da mesma forma e reciprocamente a execução dos recursos financeiros somente atenderá aos ditames do interesse público se submetida a planejamento prévio. No entanto, o financiamento da saúde, por si só, não significa injetar incondicionalmente recursos na saúde. Diversas condições e requisitos foram impostos por lei para a aplicação das verbas públicas na saúde. A primeira condição era a definição do que vem a ser ações e serviços públicos de saúde, o que somente aconteceu recentemente, com o advento da Lei Complementar acima citada (arts. $2^{\circ}$, 3ํㅜ e $4^{\circ}$ ). Antes disso, batalhas jurídicas se travaram porque os gestores de saúde, especialmente no palco de conflitos interfederativos, não reconheciam obrigatoriedade (art. $5^{\circ}$, inciso $2^{\circ}$ da CF), na Resolução no 322, de 8 de maio de 2003, quando esta, em suas quarta, quinta e sexta diretrizes, declaravam o que era e o que não era ação e serviço público de saúde. Além desses requisitos há outras condições que o conselheiro precisa conhecer, especialmente aquela que diz respeito às exigências para a consecução das transferências obrigatórias da União ou dos Estados para o município, previstas nas seções II a V, do Capítulo III, da Lei Complementar nº 141/2011. Colhem-se, dali, alguns exemplos que demonstram a enorme complexidade da questão do financiamento da saúde e que precede e se entretece, ainda, com outras questões tão complexas como as exigências orçamentárias e de execução financeira, dos quais pode-se enumerar: a constatação da aplicação dos recursos mínimos para a saúde; a manutenção de contas específicas para o recebimento dos repasses, no 
fundo municipal de saúde; o conhecimento prévio dos critérios de rateio das verbas federais a serem repassadas ao ente municipal; o conhecimento prévio do montante das verbas federais e estaduais a serem repassados anualmente ao município.

Segue-se a necessidade de se conhecer o sistema de regulação do planejamento, instituído no art. 165 da Constituição Federal, que impõe aos entes federativos e, portanto aos municípios, leis que estabeleçam o plano plurianual, as diretrizes orçamentárias e os orçamentos anuais. Tanto o plano plurianual quanto as diretrizes orçamentárias encontram-se na esfera do poder político, mas a lei orçamentária deve observar as normas gerais de direito financeiro para elaboração e controle dos orçamentos e balanços da União, dos Estados, dos Municípios e do Distrito Federal, previstos na Lei № 4.320/64 (recepcionada com status de Lei Complementar pela $\mathrm{CF} / 88$ ), bem assim a Lei de Responsabilidade Fiscal (Lei Complementar oํ 101/2000 e, por fim, a recente Lei Complementar 141/2011, que, por sua especificidade e importância para o exame do Plano de Saúde, merece ser transcrito:

Art. 30. Os planos plurianuais, as leis de diretrizes orçamentárias, as leis orçamentárias e os planos de aplicação dos recursos dos fundos de saúde da União, dos Estados, do Distrito Federal e dos Municípios serão elaborados de modo a dar cumprimento ao disposto nesta Lei Complementar.

$\S 1^{\circ} \mathrm{O}$ processo de planejamento e orçamento será ascendente e deverá partir das necessidades de saúde da população em cada região, com base no perfil epidemiológico, demográfico e socioeconômico, para definir as metas anuais de atenção integral à saúde e estimar os respectivos custos.

$\S 2^{\circ}$ Os planos e metas regionais resultantes das pactuações intermunicipais constituirão a base para os planos e metas estaduais, que promoverão a equidade interregional.

$\S 3^{\circ}$ Os planos e metas estaduais constituirão a base para o plano e metas nacionais, que promoverão a equidade interestadual.

$\S 4$ - Caberá aos Conselhos de Saúde deliberar sobre as diretrizes para o estabelecimento de prioridades.

Este substantivo influxo de normas legais que se impõe à formulação do plano municipal de saúde, tanto na perspectiva do financiamento quanto na observância das regras de planejamento público e financiamento, para além, como foi dito, das ações e serviços públicos de saúde objeto do plano propriamente dito, constituem 
mais um desafio para a subsistência do modelo de participação e controle social, porquanto a incapacidade dos conselheiros municipais de lidar com esse arcabouço jurídico resulta na deliberação e aprovação de planos de saúde que não resistem à submissão às regras acima apresentadas tornando-os passíveis de alterações posteriores, para conformá-los às leis, sem a intervenção do controle social, quando não simplesmente os tornam inexequíveis.

São muitos os esforços de tornar os conselheiros municipais (e estaduais) capazes de exercerem suas funções mediante o acréscimo de conteúdos técnicos às suas experiências pessoais. Destaque-se a atuação da Escola Nacional de Saúde Pública Sérgio Arouca, da Fundação Oswaldo Cruz que, por meio do ensino à distância (EAD), oferece curso de Capacitação de Conselheiros Municipais e Estaduais de Saúde, em cujo programa se destaca as seguintes unidades de aprendizagem que se referem ao assunto aqui tratado: Planejamento de Saúde: Agenda, Plano de Saúde, Quadro de Metas; e Planejamento em Saúde: orçamento. ${ }^{1}$

Já em 2006 esse esforço era registrado por Labra (2006, p. 208):

Várias outras iniciativas têm sido empreendidas na esfera do Ministério da Saúde para reforçar o Controle Social, das quais ressalta o Programa de Capacitação para Conselheiros levando adiante pelo Ministério da Saúde em conjunto com a Escola Nacional de Saúde Pública/Fiocruz e outras instituições, que envolveu 35 mil participantes de todo o país. Esta bem-sucedida experiência, atualmente em fase de multiplicação mediante Pólos de Educação Permanente, teve como objetivo central fornecer aos conselheiros conhecimentos e instrumentos indispensáveis para 0 aprimoramento de seu desempenho nos CS e para o exercício do controle social de maneira informada e assertiva.

Parece, no entanto, que não é o caso de transformar os conselheiros municipais de saúde em juristas ou contadores para que possam exercer suas atribuições. O modelo participativo do controle social deve encontrar outras soluções que permitam a inclusão de conselheiros de menor capacitação técnico-jurídica mas que, no entanto, tenham experiência pessoal para deliberar sobre a oportunidade e conveniência das propostas de ação e serviços públicos de saúde que constituem o plano de saúde e a programação anual de saúde.

1 cf. em http://www.ead.fiocruz.br/curso/index.cfm?cursoid=676, acesso em 31/03/2013 
Tal é a realidade do país. O esforço incessante de capacitação de conselheiros não atingirá e nem pretende atingir o objetivo de conferir-lhes plena habilitação para lidar com a inarredável e complexa regulação jurídica que informa a elaboração dos planos de saúde e seus consectários, mas pode prepará-los, dentro de um limite mínimo de aprendizado, para, quando for necessário, dialogar com técnicos que thes forem designados para auxiliá-los e alertá-los quanto à incidência das normas jurídicas e contábeis em determinada avaliação de plano de saúde.

Fung e Cifuentes, citados em Coelho (2007, p. 81), nesse sentido, o de estabelecer incentivos estruturais e metodologias participativas, argumentam que:

a capacidade dos foros participativos de contribuir para definir agendas que expressem os interesses dos mais pobres poderia ser favorecida por mecanismos institucionais e procedimentais que promovam tanto a inclusão de participantes com menor capacitação técnica e escassos recursos de comunicação, como também sua capacidade de se posicionar diante dos temas em discussão. Tais autores sugerem incentivos estruturais, metodologias participativas $e$ abordagens deliberativas como meio de aperfeiçoar a inclusão e a qualidade dos processos endógenos de formação de preferências.

Assim, ao que parece, a par dos esforços de capacitação acima apontados, outro caminho a ser trilhado é o de fornecer estrutura técnica aos Conselhos de Saúde, mediante o oferecimento de técnicos na área jurídica e contábil para que eles possam informar-se no processo deliberativo. Para citar um exemplo, a Lei que instituiu o Conselho Municipal de Saúde de Florianópolis (SC), prescreveu que esse conselho terá a Assessoria Técnica dos Profissionais da Secretaria Municipal da Saúde e Desenvolvimento Social e da Comissão Interinstitucional Municipal de Saúde (Santa Catarina, 1989). ${ }^{2}$ Por outro lado, os usuários que compõem o Conselho são representantes de diversas organizações da sociedade civil com as quais, evidentemente, podem contar, no sentido de obterem, dali, tal assessoria técnica, o que, aliás, seria mais desejável, de modo a garantir a imparcialidade no assessoramento, evitando a prevalência do poder público que ordinariamente hegemoniza os conselhos municipais de saúde, mormente nos pequenos municípios. 


\section{Conclusão}

O cotejo das diversas percepções acerca das dificuldades do modelo de participação social no planejamento da saúde pública, aliado ao complexo modelo jurídico-contábil do planejamento público é fator inibitório da atuação deliberativa e fiscalizatória dos Conselhos Municipais de Saúde, mercê da natural falta de capacitação dos conselheiros municipais, em especial, nos menores municípios do país. No entanto, essa deficiência não justifica solapar o modelo de participação social e democrática conquistado pelo movimento da reforma sanitária e insculpida na Constituição Federal de 1988 de que se constituem os conselhos de saúde. Afinal, todo o processo de produção normativa que envolve o financiamento, o planejamento público e a execução orçamentária, sobre ser realmente complexo é uma garantia de aplicação regular e apropriada das verbas públicas originárias ou transferidas de um ente federativo para outro.

Enfrentar esta dicotomia que põe de um lado essas garantias de boa aplicação do dinheiro público e de outro a inviabilidade de se apreender todo esse complexo arcabouço legal instituído em favor dessas garantias, justamente para realizá-las, não prescinde de capacitação dos conselheiros, mas não prescinde, também, de estruturação dos Conselhos Municipais de Saúde mediante a possibilidade de os conselheiros contarem com assessoria jurídico-contábil à sua disposição.

\section{Referências}

BRASIL. Constituição da República Federativa do Brasil (1988). Disponível na internet na URL: <http://www.planalto.gov.br/ccivil 03/constituicao/ConstituicaoCompilado.htm\#adct> Acesso em: 28.mar.2013.

BRASIL. Lei Federal $n^{\circ}$ 8.080, de 19 de setembro de 1980. Disponível na internet na URL: http://www.planalto.gov.br/ccivil 03/leis//8080.htm, acesso em: 28.mar.2013.

BRASIL. Lei Federal no 8.142, 28 de dezembro de 1980,. Disponível na internet na URL: http://www.planalto.gov.br/ccivil 03/leis/l8142.htm, acesso em: 28.mar.2013.

BRASIL. Emenda Constitucional no 29, de 13 de setembro de 2000. Disponível na internet na

URL: http://www.planalto.gov.br/ccivil 03/constituicao/Emendas/Emc/emc29.htm, acesso: em 28.mar.2013.

BRASIL. Lei Complementar no 101, de 4 de maio de 2000. Disponível na internet na 
URL: $\quad$ http://www.planalto.gov.br/ccivil 03/leis/lcp/lcp101.htm, acesso em: 28.mar.2013.

BRASIL. Lei Federal no 4.320, de 17 de março de 1964. Disponível na internet na URL: http://www.planalto.gov.br/ccivil 03/leis/14320.htm, acesso em: 28.mar.2013.

BRASIL. Lei Complementar no 141, de 13 de janeiro de 2012. Disponível na internet na URL: http://www.planalto.gov.br/ccivil 03/leis/lcp/Lcp141.htm, acesso em: 28.mar.2013.

BRASIL. Ministério da Saúde. Sistema de Planejamento do SUS: Uma Construção Coletiva. Série B, Textos Básicos de Saúde, Série Cadernos de Planejamento, vol. 6. Brasília : Ministério da Saúde, 2009.

BRASIL, Resolução no 333, de 4 de novembro de 2003. Ministério da Saúde, Conselho Nacional de Saúde, disponível na internet na URL: http://conselho.saude.gov.br/biblioteca/livros/resolucao 333.pdf, acesso em 31.mar.2013.

BRASIL. Resolução no 322, de 8 de maio de 2003. Ministério da Saúde, Conselho Nacional de Saúde, disponível na internet na URL: http://portalsaude.saude.gov.br/portalsaude/arquivos/pdf/2012/Set/26/resolucao CNS 322.pdf acesso em 31.mar.2013

COELHO, VSP, Democratização dos Conselhos de Saúde. Revista Novos Estudos, CEBRAPA, (78):77-92, 2007.

CUNHA, E.S.M. A efetividade deliberativa dos conselhos municipais de saúde e de criança e adolescente no Nordeste. In: AVRITZER, Leonardo (Org.). A participação social no Nordeste. (1 ed). Belo Horizonte : Ed. UFMG, 2007. p. 135-162.

LABRA, M.E., Conselho de Saúde Visões "macro" e "Micro". Civitas - Revista de Ciências Sociais; 6(1):199:221, 2006.

MARTINS, P.C., et alii, Conselhos de Saúde e a Participação Social no Brasil: Matizes da Utopia. Physis, Revista de Saúde Coletiva, Rio de Janeiro; 18(1):105-121, 2008.

SANTOS, S.F., et alii, Conselheiros Usuários do Conselho Municipal de Saúde de Belo Horizonte: características sociais e representatividade. Saúde Soc. São Paulo; 20(2): 483-495, 2011.

VAN STRALEN, C. J., et alii. Conselhos de Saúde: efetividade do controle social em municípios de Goiás e Mato Grosso do Sul. Ciência \& Saúde Coletiva; 11(3):621-632, 2006.

VIEIRA, FS. Avanços e Desafios do Planejamento do Sistema Único de Saúde. Ciência \& Saúde Coletiva; 14(supl. 1): 1.565-1.577, 2009. 